\title{
Effect of aldosterone breakthrough on albuminuria during treatment with a direct renin inhibitor and combined effect with a mineralocorticoid receptor antagonist
}

\author{
Atsuhisa Sato and Seiichi Fukuda
}

We have reported observing aldosterone breakthrough in the course of relatively long-term treatment with renin-angiotensin (RA) system inhibitors, where the plasma aldosterone concentration (PAC) increased following an initial decrease. Aldosterone breakthrough has the potential to eliminate the organ-protective effects of RA system inhibitors. We therefore conducted a study in essential hypertensive patients to determine whether aldosterone breakthrough occurred during treatment with the direct renin inhibitor (DRI) aliskiren and to ascertain its clinical significance. The study included 40 essential hypertensive patients (18 men and 22 women) who had been treated for 12 months with aliskiren. Aliskiren significantly decreased blood pressure and plasma renin activity (PRA). The PAC was also decreased significantly at 3 and 6 months; however, the significant difference disappeared after 12 months. Aldosterone breakthrough was observed in 22 of the subjects (55\%). Urinary albumin excretion differed depending on whether breakthrough occurred. For the subjects in whom aldosterone breakthrough was observed, eplerenone was added. A significant decrease in urinary albumin excretion was observed after 1 month, independent of changes in blood pressure. In conclusion, this study demonstrated that aldosterone breakthrough occurs in some patients undergoing DRI therapy. Aldosterone breakthrough affects the drug's ability to improve urinary albumin excretion, and combining a mineralocorticoid receptor antagonist with the DRI may be useful for decreasing urinary albumin excretion. When the objective is organ protection in hypertensive patients, a two-pronged approach using combination therapy to inhibit both the RA system and aldosterone may be highly effective.

Hypertension Research (2013) 36, 879-884; doi:10.1038/hr.2013.74; published online 18 July 2013

Keywords: aldosterone; aldosterone breakthrough; direct renin inhibitor; mineralocorticoid receptor antagonist; urinary albumin excretion

\section{INTRODUCTION}

The renin-angiotensin (RA) system has an important role in blood pressure regulation, and increased activity of the RA system has been reported to be involved in hypertension and organ impairment. ${ }^{1}$ Angiotensin-converting enzyme (ACE) inhibitors and angiotensin II type 1 receptor blockers (ARBs) targeting the RA system are the key drugs used in the treatment of hypertension, heart failure, renal failure and vascular disorders. ${ }^{2,3}$ The direct renin inhibitor (DRI) aliskiren is a drug that lowers blood pressure by directly blocking the renin that functions as a rate-limiting enzyme in the RA system, and it has been reported to exhibit a reliable hypotensive action similar to that of ACE inhibitors and ARBs. ${ }^{4-6}$ Moreover, good patient compliance can be obtained with aliskiren because adverse reactions are few compared with placebo and do not differ in frequency depending upon whether the usual dose or maximum dose is taken and whether the treatment is short or long term. ${ }^{7,8}$
Aliskiren differs from ACE inhibitors and ARBs in the effects that it exerts on each component of the RA system during treatment. Although aliskiren shares an inhibitory effect upon the RA system with these drugs, the characteristics of its action on the RA system are unlike anything observed heretofore. The clinical results of short-term aliskiren administration show significant reductions in plasma renin activity, plasma angiotensin I, angiotensin II (Ang II) and plasma and urinary aldosterone. ${ }^{9}$ The effect of aliskiren on PRA is particularly different from that of ACE inhibitors and ARBs, and no compensatory elevation in PRA due to RA system inhibition is observed. Accordingly, the results suggest a powerful overall inhibitory action on the RA system, which is thought to make ACE breakthrough and aldosterone breakthrough less likely to occur. ${ }^{10}$ If the potential for aldosterone breakthrough is reduced, then aliskiren can be expected to offer great advantages compared with ACE inhibitors and ARBs in terms of organ-protective effects. Another 
merit is that the entire RA system, including aldosterone, can be inhibited with a single DRI.

Thus far, we have reported observing aldosterone breakthrough in the course of relatively long-term treatment with an ACE inhibitor, where the plasma aldosterone concentration (PAC) increased following an initial decrease. ${ }^{11,12}$ Aldosterone breakthrough has the potential to eliminate the organ-protective effects of treatment. The same is true of treatment with an ARB, where it has been reported that long-term aldosterone inhibition is impossible. ${ }^{13,14}$ Even increasing the dosage of an ACE inhibitor or ARB, or using them concomitantly, is not considered an effective measure against aldosterone breakthrough, making it necessary to add a mineralocorticoid receptor (MR) antagonist (aldosterone blocker). ${ }^{15-17}$ While the mechanism of aldosterone breakthrough remains unclear, the incomplete inhibition of the RA system is thought to be one factor. ${ }^{12}$ Accordingly, aldosterone breakthrough may not occur during treatment with a DRI, which should afford more potent inhibition of the RA system compared with an ACE inhibitor or ARB. However, few studies have thus far focused on aldosterone breakthrough during treatment with a DRI.

We thereupon conducted a study in essential hypertensive patients to determine whether aldosterone breakthrough occurred during treatment with the DRI aliskiren and to ascertain its clinical significance if it did occur. We then investigated the combined effect of a DRI and MR antagonist in patients who exhibited aldosterone breakthrough.

\section{METHODS}

The study included 40 essential hypertensive patients ( 18 men and 22 women; mean age, $67 \pm 10$ years) who were outpatients at our hospital and had not previously received aliskiren treatment. The patients were then treated for 12 months with either aliskiren alone or a combination of aliskiren and the long-acting calcium channel blocker amlodipine, which is not thought to affect PAC. ${ }^{18-20}$ In all subjects, PRA and PAC were measured before the start of treatment, and primary aldosteronism was excluded. Other secondary hypertension was also excluded. After confirming that aliskiren was not contraindicated, we started treatment with $150 \mathrm{mg}$ administered once daily in the morning. No other RA system inhibitors were added during the course of the study, and the dosage of aliskiren was adjusted to control blood pressure, with possible increases up to a maximum dosage of $300 \mathrm{mg}$. Subjects were asked to visit the hospital 2 weeks after starting aliskiren, and then, if there were no problems, a visit schedule of every 4 weeks was permitted. PRA and the PAC were measured before treatment and after 3, 6 and 12 months of treatment.

Blood pressure was measured in a sitting position at rest in the outpatient clinic. The mean of two stable values was taken as the blood pressure value. The radial artery pulse was measured over $30 \mathrm{~s}$. The blood sampling conditions for PRA and the PAC were kept uniform throughout the treatment whenever possible, with blood samples taken after the subjects had remained seated for $\sim 10 \mathrm{~min}$ at the time of the outpatient examination. The assay sensitivity for PRA was $0.1-20 \mathrm{ng} \mathrm{ml}^{-1}$ per hour (Renin activity, TFB Corporation, Tokyo, Japan), and it was $25-1600 \mathrm{pg} \mathrm{ml}^{-1}$ for the PAC (SPAC-S Aldosterone Kit, Dai-ichi Radioisotope, Tokyo, Japan). All lifestyle guidance regarding diet during treatment, exercise therapy and so on was based on The Japanese Society of Hypertension Guidelines for the Management of Hypertension (JSH 2009), as was all treatment for hypertension administered during the course of the study. ${ }^{2}$

As in our previous reports, ${ }^{11,15}$ aldosterone breakthrough was defined as any increase in the PAC from the baseline level after treatment with aliskiren, even if the PAC was within the so-called normal range. In this study, $50 \mathrm{mg}$ of the selective MR antagonist eplerenone was additionally administered once daily in the morning to the 22 subjects who exhibited aldosterone breakthrough and showed no decrease in albuminuria. The amount of albumin excreted in the urine was evaluated at 1 and 3 months after the addition of eplerenone to the regimen. As eplerenone is contraindicated in the presence of hyperkalemia $\left(\geqslant 5.0 \mathrm{mEql}^{-1}\right)$, moderate or severe renal impairment (creatinine clearance $<50 \mathrm{ml} \mathrm{min}^{-1}$ ), and diabetes with microalbuminuria or proteinuria in Japan, for each subject, it was first confirmed that eplerenone was not contraindicated. Moreover, changes in the serum potassium level and other electrolytes were periodically monitored throughout the study. The study protocol was approved by the Committee on Medical Research Ethics of our hospital.

Measurements are presented as the mean \pm s.d. Statistical significance was evaluated by one-way or two-way analysis of variance with repeated measures, as appropriate. The two-group paired $t$-test was used to test the significance of differences between pairs of groups with the level of significance set at $<5 \%$. Pearson's correlation coefficient was used to measure the linear interdependence between two variables.

\section{RESULTS}

All 40 of the included patients visited our outpatient clinic periodically and were followed for 12 months. Table 1 shows the clinical data before aliskiren administration and after 12 months of administration in the study subjects. All subjects were essential hypertensive patients for whom secondary hypertension had been excluded, and they were either without antihypertensive treatment or had been unable to achieve the target reduction in blood pressure even after being treated with amlodipine. Blood pressure before treatment with aliskiren was $158 \pm 7 / 90 \pm 7 \mathrm{~mm} \mathrm{Hg}$, and urine albumin was $102 \pm 118 \mathrm{mg} \mathrm{g} \mathrm{Cr}^{-1}$. Beginning 1 month after the addition of aliskiren, blood pressure decreased significantly, and the hypotensive effect was sustained even 12 months later (Figure 1). PRA decreased significantly from month 3 onward, reaching its lowest level after 12 months. The PAC decreased significantly 3 and 6 months after the start of treatment with aliskiren. However, the significant difference disappeared after 12 months, with the value returning nearly to the pretreatment level (Figure 2).

When we investigated the PRA and PAC of each subject at 12 months, we found that PRA showed a significant decrease compared with that before the addition of aliskiren in all subjects, whereas the

Table 1 The clinical data before aliskiren administration and after 12 months of administration in the study subjects

\begin{tabular}{|c|c|c|}
\hline & Pre-treatment & Post-treatment ( $48 w)$ \\
\hline Men/Women & $18 / 22$ & \\
\hline Age (years) & $67 \pm 10$ & \\
\hline BMI & $23 \pm 4$ & \\
\hline $\mathrm{SBP}(\mathrm{mm} \mathrm{Hg})$ & $158 \pm 7$ & $136 \pm 7^{*}$ \\
\hline DBP (mm Hg) & $90 \pm 7$ & $82 \pm 5$ \\
\hline PRA (ng ml ${ }^{-1}$ per hour) & $1.83 \pm 1.20$ & $0.28 \pm 0.22 *$ \\
\hline PAC (pg ml-1) & $118 \pm 44$ & $104 \pm 45$ \\
\hline $\mathrm{BNP}\left(\mathrm{pg} \mathrm{ml^{-1 }}\right)$ & $31.1 \pm 25.8$ & $25.0 \pm 18.8$ \\
\hline Albuminuria $\left(\mathrm{mggCr}^{-1}\right)$ & $101.8 \pm 117.7$ & $63.3 \pm 93.0^{*}$ \\
\hline BUN (mgdl-1) & $19.9 \pm 6.3$ & $18.8 \pm 5.0$ \\
\hline $\mathrm{Cr}\left(\mathrm{mgdl}{ }^{-1}\right)$ & $0.78 \pm 0.13$ & $0.83 \pm 0.15$ \\
\hline eGFR $\left(\mathrm{ml} \mathrm{min}-1\right.$ per $\left.1.73 \mathrm{~m}^{2}\right)$ & $71.3 \pm 12.3$ & $68.5 \pm 19.7$ \\
\hline $\mathrm{UA}\left(\mathrm{mg} \mathrm{dl}^{-1}\right)$ & $5.7 \pm 1.2$ & $6.0 \pm 1.1$ \\
\hline $\mathrm{Na}\left(\mathrm{mEq} \mathrm{I}^{-1}\right)$ & $141 \pm 2$ & $141 \pm 2$ \\
\hline$K\left(m E q I^{-1}\right)$ & $4.3 \pm 0.3$ & $4.3 \pm 0.3$ \\
\hline $\mathrm{Ca}\left(\mathrm{mg} \mathrm{dl}^{-1}\right)$ & $9.4 \pm 0.4$ & $9.3 \pm 0.5$ \\
\hline $\mathrm{IP}(\mathrm{mgdl}-1)$ & $3.5 \pm 0.4$ & $3.8 \pm 0.5$ \\
\hline HS-CRP (mg dl $\left.{ }^{-1}\right)$ & $513 \pm 478$ & $427 \pm 379$ \\
\hline
\end{tabular}

Abbreviations: BMI, body mass index; BNP, brain natriuretic peptide; BUN, blood urea nitrogen; DBP, diastolic blood pressure; eGFR, estimated glomerular filtration rate; HS-CRP high sensitivity C-reactive protein; IP, inorganic phosphorus; SBP, systolic blood pressure; PAC, plasma aldosterone concentration; PRA, plasma renin activity; UA, uric acid. PAC, plasma aldosterone concentration;
Data are presented as the means \pm s.d.

${ }^{*} P<0.05$ vs. pretreatment value. 


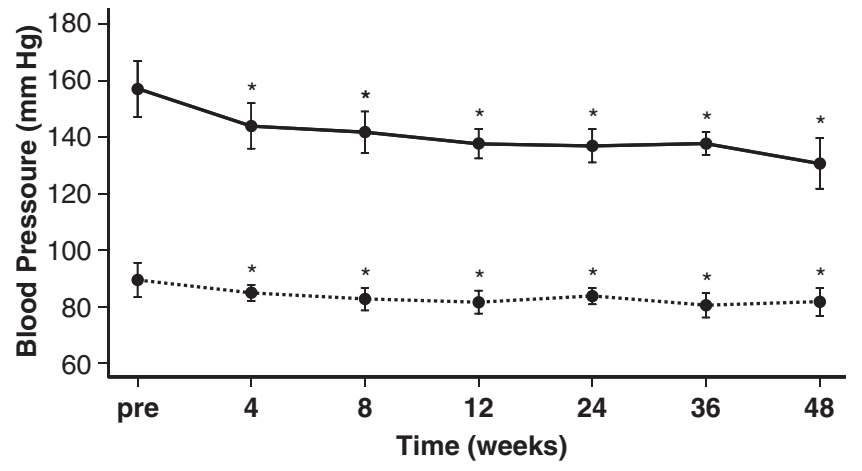

Figure 1 Changes in systolic blood pressure (solid line) and diastolic blood pressure (dotted line) during antihypertensive treatment with aliskiren in patients with essential hypertension. Data represent the mean \pm s.d. ${ }^{*} P<0.05$ vs. each baseline value.
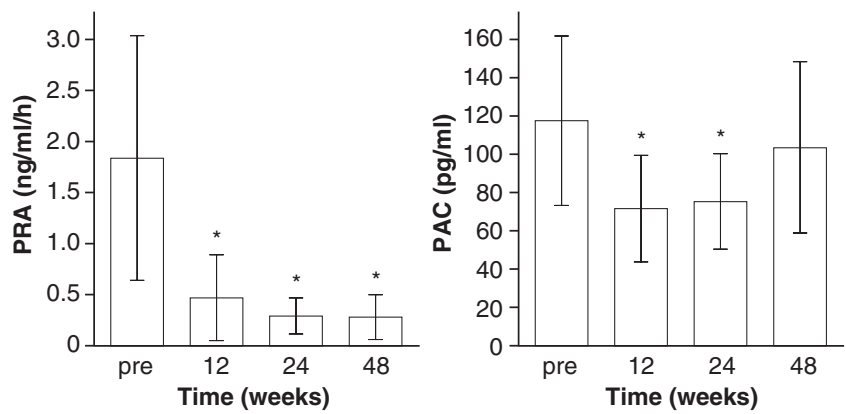

Figure 2 Changes in plasma renin activity (PRA) and the plasma aldosterone concentration (PAC) before and after treatment with aliskiren in patients with essential hypertension. Data represent the mean \pm s.d. ${ }^{*} P<0.05$ vs. each baseline value.

PAC had increased from the pretreatment level despite continued inhibition of PRA, resulting in aldosterone breakthrough in 22 of the subjects (55\%). Among all the clinical data, only albuminuria significantly differed if breakthrough occurred (Figure 3). The breakthrough $(+)$ group showed no significant difference from the breakthrough (-) group in parameters such as blood pressure, electrolytes, general biochemical findings, brain natriuretic peptide and high-sensitivity C-reactive protein. We analyzed the correlation between the PAC and albuminuria in the 22 patients showing aldosterone breakthrough. Although the number of patients analyzed was too small to allow any definite conclusion, this analysis revealed no significant correlation (data not shown). Similarly, in our previous study involving patients with type 2 diabetes mellitus, there was no correlation between the PAC and albuminuria after aldosterone breakthrough. ${ }^{15}$

For the 22 subjects in whom aldosterone breakthrough was observed in the absence of an improvement in albuminuria, eplerenone was added to the regimen. Blood pressure showed a decreasing tendency at 1 month and had decreased significantly after 3 months (from $136 \pm 9 / 81 \pm 7$ to $130 \pm 7 / 76 \pm 7 \mathrm{~mm} \mathrm{Hg}$ ). However, a significant decrease in albuminuria was observed after 1 month, without significant blood pressure changes (Figure 4). There was no significant correlation between the level of albuminuria and blood pressure at 3 months (data not shown). Patients receiving the combination therapy with aliskiren and eplerenone showed no problematic adverse reactions such as hyperkalemia. The serum potassium level was $4.2 \pm 0.3 \mathrm{mEql}^{-1}$ before starting eplerenone and $4.4 \pm 0.4 \mathrm{mEql}^{-1}$ after 3 months of eplerenone treatment.
Although all patients in this study received advice for a low salt diet based on JSH2009 from our facility's dietician, salt intake was not directly evaluated during treatment with aliskiren. However, during the follow-up period, there was no major change in the lifestyle or diet of any patient that could have seriously affected the study. It is therefore likely that salt intake during the follow-up period was relatively constant in each patient. Salt intake was unlikely to have a major influence on the results and conclusions of this study, as aldosterone breakthrough was judged based on changes in the PAC of individual patients.

\section{DISCUSSION}

This study demonstrated that aldosterone breakthrough can occur in some patients undergoing DRI therapy, directly blocking renin, which functions as the rate-limiting enzyme in the RA system, when the treatment is of relatively long duration. Aldosterone breakthrough affects the drug's ability to improve albuminuria, and we found that combining an MR antagonist with the DRI was useful in decreasing albuminuria. These results are comparable to the findings obtained when MR antagonists have been added to ACE inhibitors and ARBs. ${ }^{13-17}$ Certain clinical problems are thought to be common to all RA system inhibitors, including DRIs. When the objective is organ protection in hypertensive patients, a two-pronged approach using combination therapy to inhibit both the RA system and aldosterone is thought to be highly effective.

Below, we attempt to summarize three aspects of the results of this study. First, aldosterone breakthrough occurred even with DRI therapy. Although the plasma Ang II concentration was not measured in this study, PRA was powerfully and significantly inhibited in all subjects after 12 months of treatment, and the rate of decrease in the PAC from the pretreatment level at 6 months was far greater when compared with any results on ACE inhibitors that we have reported to date. This suggests that aliskiren powerfully inhibits the RA system, including aldosterone, for up to 6 months of treatment. However, the PAC returned to the pretreatment level after 12 months even though PRA was inhibited. When ACE inhibitors are used in patients with chronic heart failure, an increase occurs in plasma Ang II following an initial decrease, confirming a positive correlation between the Ang II concentration and the PAC. ${ }^{21}$ In patients taking ACE inhibitors, aldosterone breakthrough is thought to occur by such mechanisms as Ang II production via non-ACE routes or even the ACE route itself. ${ }^{12}$ Moreover, AT2 receptor-mediated aldosterone production has also been reported to occur when ARBs are administered. ${ }^{14}$ However, none of the clinical studies reported thus far have found the frequency of aldosterone breakthrough to differ greatly between patients treated with ACE inhibitors and those receiving ARBs. ${ }^{22}$ This strongly suggests that factors other than the RA system are involved in the main mechanism of aldosterone breakthrough. Aldosterone regulation is clearly dependent on the RA system, that is, Ang II, for up to $\sim 6$ months, but the major part of that regulation may become dissociated from the RA system over the relatively long term, resulting in breakthrough. When treatment with ACE inhibitors is followed up over a longer period of time, an increase in PAC is observed in almost all subjects. ${ }^{23}$ The results of future long-term treatment will be important, and it will be interesting to determine whether PAC remains inhibited or whether aldosterone breakthrough eventually occurs in most subjects, as it does with ACE inhibitors.

The second aspect of consideration is the clinical significance of aldosterone breakthrough. There are few reports on how the presence or absence of aldosterone breakthrough during treatment with ACE inhibitors or $\mathrm{ARBs}$ is involved in blood pressure control. ${ }^{24}$ 

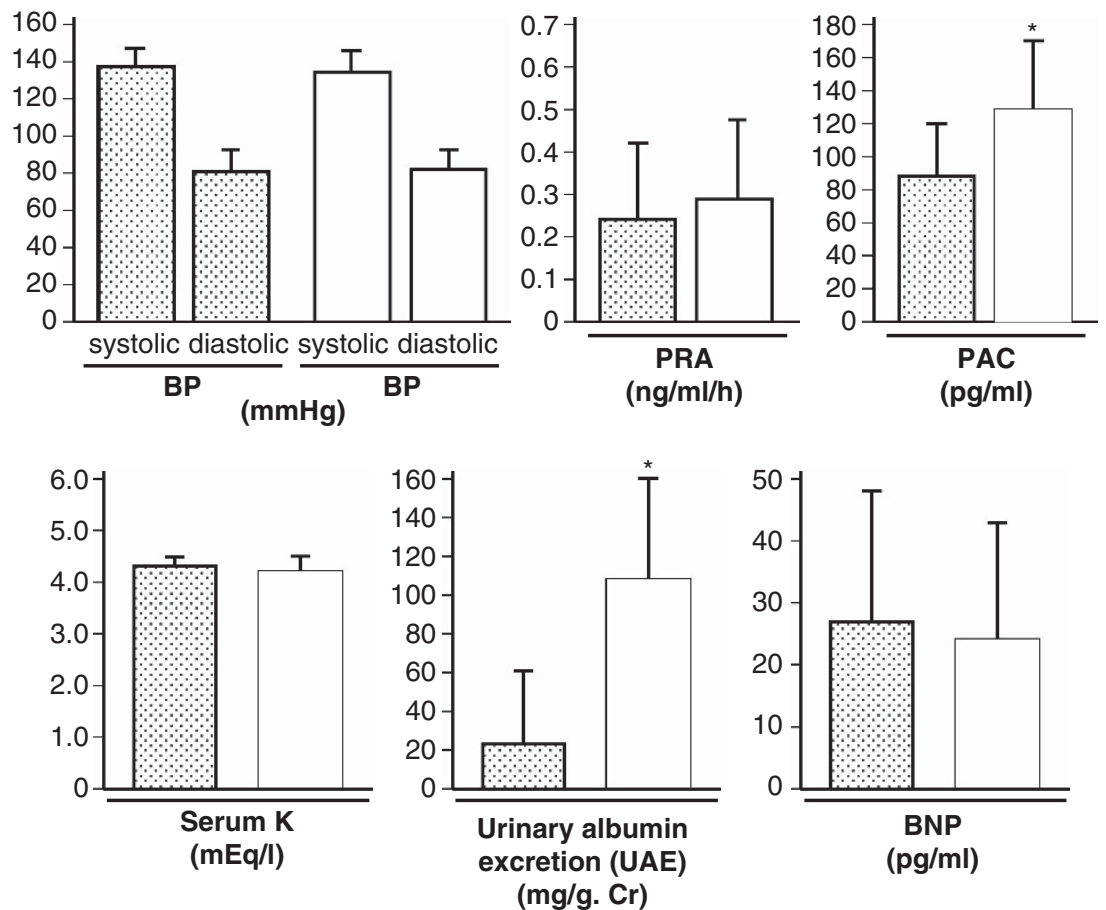

Figure 3 Changes in blood pressure (BP), plasma renin activity (PRA), plasma aldosterone concentration (PAC), serum potassium (K), urinary albumin excretion (UAE) and brain natriuretic peptide (BNP) before and after treatment with aliskiren in patients without aldosterone breakthrough (dotted column) or with aldosterone breakthrough (open column). Data represent the mean \pm s.d. ${ }^{*} P<0.05$ vs. value with breakthrough ( - ) group.

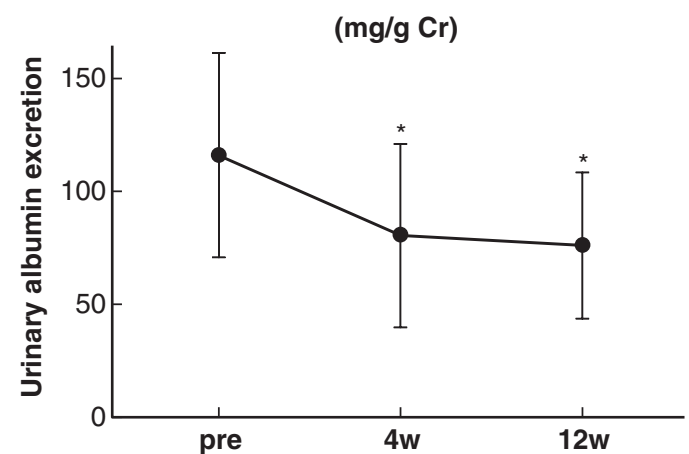

Figure 4 Changes in UAE before and after the addition of eplerenone to aliskiren in patients with essential hypertension. Data represent the mean \pm s.d. ${ }^{*} P<0.05$ vs. baseline value.

Rocha et al. ${ }^{25}$ reported that stroke-prone spontaneously hypertensive rats fed a high-sodium diet developed severe hypertension, malignant nephrosclerosis and proteinuria, but all were alleviated by ACE inhibitors. However, they also demonstrated that the renal protective effect of ACE inhibitors was completely eliminated when aldosterone was administered. Clinically, this coincides with the condition under which aldosterone breakthrough is observed during treatment with ACE inhibitors. Both ACE inhibitors and ARBs have a potent renal protective effect, and the aldosterone-inhibiting effect is one responsible mechanism. Continuous inhibition of aldosterone is thought to be a major key to sustaining the renal protective effect of RA system inhibitors. Indeed, ACE inhibitors or ARBs are often the first drugs used for renal protection in chronic kidney disease, but even when these RA system-inhibiting drugs are used, there may be no reduction in albuminuria, or albuminuria may develop during the course of treatment. ${ }^{26-28}$ It is well known that the renal protective effect of RA system inhibitors is not sustained over the course of chronic treatment.

Aliskiren is expected to have a renal protective effect independent of blood pressure because it strongly accumulates in the kidneys, reaching a renal concentration that is 50 times that of the plasma. ${ }^{29}$ Aliskiren triggers an increase in renal blood flow and a natriuretic effect, and its effect is stronger than that of ACE inhibitors or ARBs. ${ }^{30}$ Following the uptake of aliskiren by renin-producing cells, the drug binds to renin granules inside the cells, inactivating stored renin before secretion. ${ }^{31}$ Aliskiren in the Evaluation of Proteinuria in Diabetes was a double-blind, placebo-controlled study that investigated the effect on urinary albumin when aliskiren was added to a basic regimen of an ARB in patients with diabetic nephropathy. ${ }^{32}$ Blood pressure was ultimately controlled to a mean of $\sim 135 / 78 \mathrm{~mm} \mathrm{Hg}$ in both the groups, and in the aliskiren group, the early morning urinary albumin/creatinine ratio was significantly reduced. In the present study, aliskiren inhibited albuminuria by significantly inhibiting the PAC at 6 months. These results are similar to those of the Aliskiren in the Evaluation of Proteinuria in Diabetes study, and albuminuria can be significantly reduced by short-term treatment with aliskiren administered alone or as an add-on to another RA system inhibitor. However, in the present study, albuminuria did not decrease in subjects in whom aldosterone breakthrough was observed after 12 months of treatment. This course is common to ACE inhibitors and ARBs, suggesting that inhibition of aldosterone activity is involved in the antialbuminuria effect of aliskiren. Aldosterone breakthrough must be treated to sustain the organ-protective effect of aliskiren, among other reasons.

Finally, the third aspect of consideration is the use of DRIs in combination with an MR antagonist. The combined use of ACE inhibitors and ARBs has been expected to offer a combined effect 
Short time ( RAA inhibition ) Relative long time ( RA inhibition + MR inhibition )

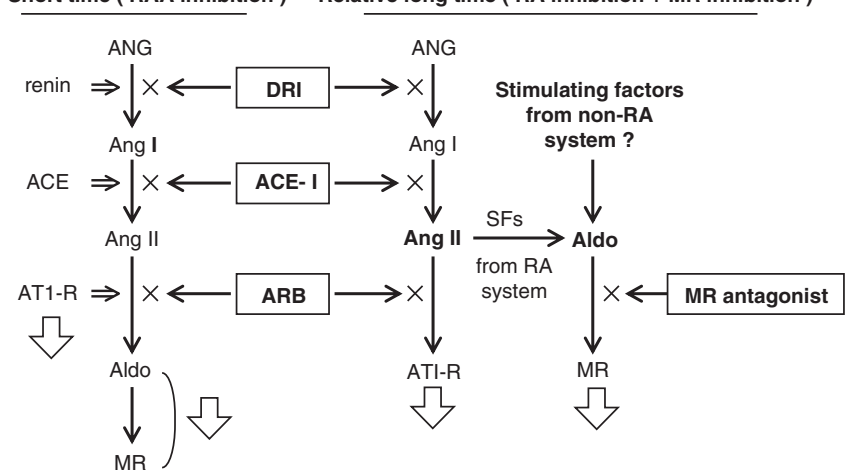

Figure 5 In a short period after treatment with a renin-angiotensin (RA) system inhibitor, the plasma aldosterone concentration (PAC) significantly decreased because the PAC is primarily controlled by angiotensin II. Shortterm suppression of the PAC is similarly observed in all RA system inhibitors, and the PAC can be suppressed by blockading one point in the RA system (left panel). However, with relative long-term treatment ( $>6$ months) using an RA system inhibitor, continuous suppression of the PAC becomes difficult, and aldosterone-stimulating factors from non-RA systems may greatly increase. Therefore, even if the inhibitor blocks the RA system, the PAC is not controlled completely. For the long-term suppression of harmful aldosterone actions, it is more effective to use one RA system inhibitor in combination with a mineralocorticoid receptor (MR) antagonist (right panel). RAA, renin-angiotensin-aldosterone, ANG, angiotensinogen; Ang I, angiotensin I; ACE, angiotensin-converting enzyme; Ang II, angiotensin II; AT1-R, angiotensin II type 1 receptors; Aldo, aldosterone; $M R$, mineralocorticoid receptors; DRI, direct renin inhibitor; ACE-I, ACE inhibitor; ARB, angiotensin receptor blocker.

affording further organ protection. However, no combined effect of ACE inhibitors and ARBs was reported by either the Valsartan in Acute Myocardial Infarction study ${ }^{33}$ or ONTARGET. ${ }^{34}$ Another relevant study was Aliskiren in Type 2 Diabetes using cardio-renal end points, which investigated the efficacy and safety of aliskiren in patients with type 2 diabetes and renal impairment or decreased renal function who were at high risk for cardiovascular and renal events. ${ }^{35}$ In the wake of the Aliskiren in the Evaluation of Proteinuria in Diabetes study, there were great expectations for a combined effect with ACE inhibitors or ARBs; however, the interim analysis showed a high incidence of adverse events such as nonlethal stroke, renal complications and hyperkalemia in the combination treatment group, leading to the early discontinuation of the study. Subsequently, the combined use of aliskiren and ACE inhibitors or ARBs was contraindicated in patients with the complication of diabetes. With the exception of small-scale clinical studies, no evidence exists at present to support the combined use of ACE inhibitors, ARBs and DRIs.

However, numerous studies have demonstrated a combined effect of ACE inhibitors or ARBs with MR antagonists. Randomized Aldactone Evaluation Study, ${ }^{36}$ The Eplerenone Post-Acute Myocardial Infarction Heart Failure Efficacy and Survival Study, ${ }^{37}$ Eplerenone in Mild Patients Hospitalization and Survival Study in Heart Failure ${ }^{38}$ and the $4 \mathrm{E}$-study ${ }^{39}$ targeted the heart, and a number of other studies have targeted the kidneys. ${ }^{15,16,40-44}$ Although no other study has thus far investigated the combined effect of DRIs and MR antagonists, the present study found a combined effect for the two, albeit limited to a small number of cases. If aldosterone breakthrough can occur during treatment with DRIs as it can with ACE inhibitors and ARBs, then the combined use of DRIs and MR antagonists may be useful. It should also be noted that the present study did not observe hyperkalemia or other adverse reactions that would present a cause for concern. In the future, we plan to increase the number of subjects to investigate the combined efficacy of DRIs and MR antagonists.

In conclusion, aldosterone breakthrough is thought to be a clinical problem common to all RA system inhibitors, including DRIs. Our results suggest that a two-pronged approach using combination therapy to inhibit both the RA system and aldosterone may be highly effective when the goal of treatment is organ protection in a hypertensive patient (Figure 5).

\section{CONFLICT OF INTEREST}

The authors declare no conflict of interest.

1 Dzau VJ. Theodore Cooper Lecture. Tissue angiotensin and pathobiology of vascular disease: a unifying hypothesis. Hypertension 2001; 37: 1047-1052.

2 The Japanese Society of Hypertension Committee. The Japanese Society of Hypertension Committee for Guidelines for the Management of Hypertension. Hypertens Res 2009; 32: 1-107.

3 Zaman MA, Oparil S, Calhoun DA. Drugs targeting the renin-angiotensin-aldosterone system. Nat Rev Drug Discov 2002; 1: 621-636.

4 Stanton A, Jensen C, Nussberger J, Obrien E. Blood pressure lowering in essential hypertension with an oral renin inhibitor, aliskiren. Hypertension 2003; 42: 1137-1143.

5 Gradman AH, Schmieder RE, Lins RL, Nussberger J, Chiang Y, Bedigian MP. Aliskiren, a novel orally effective renin inhibitor, provides dose-dependent antihypertensive efficacy and placebo-like tolerability in hypertensive patients. Circulation 2005; 111: 1012-1028.

6 Krone W, Hanefeld M, Meyer HF, Jung T, Bartlett M, Yeh CM, Rajman I, Prescott MF, Dole WP. Comparative efficacy and safety of aliskrein and irbesartan in patients with hypertension and metabolic syndrome. J Hum Hypertens 2011; 25: 186-195.

7 Kushiro T, Itakura H, Abo Y, Gotou H, Terao S, Keefe DL. Aliskrein, a novel oral renin inhibitor, provides dose-dependent efficacy and placebo-like tolerability in Japanese patients with hypertension. Hypertens Res 2006; 29: 997-1005.

8 White WB, Bresalier R, Kaplan AP, Palmer BF, Riddell RH, Lesogor A, Chang W, Keefe DL. Safety and tolerability of the direct renin inhibitor aliskiren: a pooled analysis of clinical experience in more than 12000 patients with hypertension. J Clin Hypertens 2010; 12: 765-775.

9 Nussberger J, Wuerzer G, Jensen C, Brunner HR. Angiotensin II suppression in humans by the orally active renin inhibitor aliskiren (SPP100). Comparison with enalapril. Hypertension 2002; 39: e1-e8.

10 Persson F, Lewis JB, Lewis EJ, Rossing P, Hollenberg NK, Parving HH. Impact of aliskiren treatment on urinary aldosterone levels in patients with type 2 diabetes and nephropathy: an AVOID substudy. J Renin Angiotensin Aldosterone Syst 2012; 13: 118-121.

11 Sato A, Saruta T. Aldosterone escape during angiotensin-converting enzyme inhibitor therapy in essential hypertensive patients with left ventricular hypertrophy. J Int Med Res 2001; 29: 13-21.

12 Sato A, Saruta T. Aldosterone breakthrough during angiotensin-converting enzyme inhibitor therapy. Am J Hypertens 2003; 16: 781-788.

13 Yoneda T, Takeda Y, Usukura M, Oda N, Takata H, Yamamoto Y, Karashima S, Yamagishi M. Aldosterone breakthrough during angiotensin II receptor blockade in hypertensive patients with diabetes mellitus. Am J Hypertens 2007; 20: 1329-1333.

14 Naruse M, Tanabe A, Sato A, Takage S, Tsuchiya K, Imaki T, Takano K. Aldosterone breakthrough during angiotensin II receptor antagonist therapy in stroke-prone spontaneously hypertensive rats. Hypertension 2002; 40: 28-33.

15 Sato A, Hayashi K, Naruse M, Saruta T. Effectiveness of aldosterone blockade in patients with diabetic nephropathy. Hypertension 2003; 41: 64-68.

16 Sato A, Hayashi K, Saruta T. Antiproteinuric effects of mineralocorticoid receptor blockade in patients with chronic renal disease. Am J Hypertens 2005; 18: 44-49.

17 Sato A, Saruta T, Funder JW. Combination therapy with aldosterone blockade and renin-angiotensin inhibitors confers organ protection. Hypertens Res 2006; 29 : 211-216.

18 Abe M, Okada K, Maruyama N, Matsumoto S, Maruyama T, Fujita T, Matsumoto K, Soma M. Benidipine reduces albuminuria and plasma aldosterone in mild-to-moderate stage chronic kidney disease with albuminuria. Hypertens Res 2011; 34: 268-273.

19 Kondo T, Goto R, Sonoda K, Yasuda T, Ono K, Takaki Y, Yatsuda R, Miyamura N, Araki E. Plasma renin activity and aldosterone concentration are not altered by the novel calcium channel antagonist, azelnidipine, in hypertensive patients. Inter Med 2010; 49: 637-643.

20 Konoshita T, Makino Y, Kimura T, Fujii M, Wakahara S, Arakawa K, Inoki I, Nakamura H, Miyamori I, the Genomic Disease Outcome Consortium (G-DOC) Study Investigators. A new-generation N/L-type calcium channel blocker leads to less activation of the renin-angiotensin system compared with conventional $L$ type calcium channel blocker. J Hypertens 2010; 28: 2156-2160. 
21 Van de Wal RMA, Plokker HWM, Lok DJA, Boomsma F, van de Horst FAL, Van Veldhisen DJ, van Gilst WH, Voors AA. Determinants of increased angiotensin II level in severe chronic heart failure patients despite ACE inhibition. Int J Cardiol 2006; 106: 367-372.

22 Bomback AS. The incidence and implications of aldosterone breakthrough. Nat Clin Pract Nephrol 2007; 3: 486-492.

23 Sato A, Suzuki Y, Shibata H, Saruta T. Plasma aldosterone concentrations are not related to the degree of angiotensin-converting enzyme inhibition in essential hypertensive patients. Hypertens Res 2000; 23: 25-31.

24 Borghic C, Boschi S, Ambrosioni E, Melandri G, Branzi A, Magnani B. Evidence of a partial escape of renin-angiotensin-aldosterone blockade in patients with acute myocardial infarction treated with ACE inhibitors. J Clin Pharmacol 1993; 33: 40-45.

25 Rocha R, Chander PN, Zuckerman A, Stier CT Jr. Role of aldosterone in renal vascular injury in stroke-prone hypertensive rats. Hypertension 1999; 33: 232-237.

26 Robles NR, Velasco J, Espinosa J, Mena C, Angulo E, on behalf of the MICREX Group Investigators. Persistent microalbuminuria after treatment with renin-angiotensin axis blockers: causes and results of treatment intensification. J Renin Angiotens Aldo Syst 2011; 12: 333-339.

27 Cerezo C, Ruilope LM, Segura J, Garcia-Donaire JA, de la Cruz JJ, Banegas JR, Waeber $\mathrm{B}$, Rabelink TJ, Messerli FH. Microalbuminuria breakthrough under chronic reninangiotensin-aldosterone system suppression. J Hypertens 2012; 30: 204-209.

28 Shiigai T, Shichiri M. Late escape from the antiproteinuric effect of ACE inhibitors in nondiabetic renal disease. Am J Kidney Dis 2001; 37: 477-483.

29 Feldman DL, Jin L, Xuan H, Contrepas A, Zhou Y, Webb RL, Mueller DN, Feldt S, Cumin F, Maniara W, Persohn E, Schuetz H, Jan Danser AH, Nguyen G. Effects of aliskiren on blood pressure, albuminuria, and (pro)renin receptor expression in diabetic TG(mRen-2927 rats. Hypertension 2008; 52: 130-136.

30 Fisher NDL, Jan Danser AH, Nussberger J, Dole WP, Hollenberg NK. Renal and hormonal responses to direct renin inhibition with aliskiren in healthy humans. Circulation 2008; 117: 3199-3205.

31 Krop M, Garrelds IM, de Bruin RJA, van Gool JMG, Fisher NDL, Hollenberg NK, Jan Danser AH. Aliskiren accumulates in renin secretory granules and binds plasma protein. Hypertension 2008; 52: 1076-1083.

32 Parving $\mathrm{HH}$, Persson F, Lewis JB, Hollenberg NK. Aliskiren combined with losartan in type 2 diabetes and nephropathy. N Engl J Med 2008; 358: 2433-2446.

33 Pfeffer MA, McMurray JJ, Velazquez EJ, Rouleau JL, Kober L, Maqqioni AP, Solomon SD, Swedberg K, Van de Werf F, White H, Leimberger JD, Henis M, Edwards S Zelenkofske S, Sellers MA, Califf RM, Valsartan in Acute Myocardial Infarction Trial Investigators. Valsartan, captopril, or both in myocardial infarction complicated by heart failure, left ventricular dysfunction, or both. N Engl J Med 2003; 349: 1893-1906.
34 ONTARGET InvestigatorsYusuf S, Teo KK, Poque J, Dyal L, Copland I, Schumacher H, Dagenais G, Sleight $P$, Anderson C. Telmisartan, ramipril, or both in patients at high risk for vascular events. N Engl J Med 2008; 358: 1547-1559.

35 Parving HH, Brenner BM, McMurray JJV, de Zeeuw D, Haffner SM, Solomon SD, Chaturvedi N, Ghadanfar M, Weissbach N, Xiang Z, Armbrecht J, Pfeffer MA. Aliskiren trial in type 2 diabetes using cardio-renal endopoints (ALTITUDE): rationale and study design. Nephrol Dial Transplant 2009; 24: 1663-1671.

36 Pitt B, Zannad F, Remme W, Cody R, Castaigne A, Perez A, Palensky J, Wittes J, for The Randomized Aldactone Evaluation Study Investigators. The effect of spironolactone on morbidity and mortality in patients with severe heart failure. N Engl J Med 1999; 341: 709-717.

37 Pitt B, Remme W, Zannad F, Neaton J, Martinez F, Roniker B, Bittman R, Hurley S Kleiman J, Gatlin M, for The Eplerenone Post-Acute Myocardial Infarction Heart Failure Efficacy and Survival Study Investigators. Eplerenone, a selective aldosterone blocker in patients with left ventricular dysfunction after myocardial infarction. N Engl J Med 2003; 348: 1309-1321.

38 Zannad F, McMurray JJV, Krum H, van Veldhuisen DJ, Swedberg K, Shi H, Vincent J, Pocock SJ, Pitt B, for the EMPHASIS-HF Study Group. Eplrerenone in patients with systolic heart failure and mild symptoms. N Engl J Med 2011; 364 $11-21$.

39 Pitt B, Reichek N, Willenbrock R, Zannad F, Phillips RA, Roniker B, Kleiman J, Krause $\mathrm{S}$, Burns D, Williams GH. Effects of eplerenone, enalapril, and eplerenone/enalapril in patients with essential hypertension and left ventricular hypertrophy. The 4E-Left Ventricular Hypertrophy Study. Circulation 2003; 108: 1831-1838.

40 Rossing K, Schjoedt KJ, Smidt UM, Boomsma F, Parving HH. Beneficial effects of adding spironolactone to recommended antihypertensive treatment in diabetic nephropathy. Diabetes Care 2005; 28: 2106-2112.

41 Schjoedt KJ, Rossing K, Juhl TR, Boomsma F, Tarnow L, Rossing P, Parving HH. Beneficial impact of spironolactone on nephritic range albuminuria in diabetic nephropathy. Kidney Int 2006; 70: 536-542.

42 Bianchi S, Bigazzi R, Campese VM. Antagonists of aldosterone and proteinuria in patients with CKD: An uncontrolled pilot study. Am J Kidney Dis 2005; 46: 45-51.

43 Chrysostomou A, Pedagogos E, MacGregor L, Becker GJ. Double-blind, placebocontrolled study on the effect of the aldosterone receptor antagonist spironolactone in patients who have persistent proteinuria and are on long-term angiotensin-converting enzyme inhibitor therapy, with or without an angiotensin II receptor blocker. Clin J Am Soc Nephrol 2006; 1: 256-262.

44 Epstein M, Williams GH, Weinberger M, Lewin A, Krause S, Mukherjee R, Patni R, Beckerman B. Selective aldosterone blockade with eplerenone reduces albuminuria in patients with type 2 diabetes. Clin J Am Soc Nephrol 2006; 1: 940-951. 